\title{
School food and nutrition: developing the evidence base for policy
}

Worldwide, governments develop policies to improve the welfare of their children, focusing especially on health, education and environmental and social security ${ }^{(1)}$. The basis for these policies is quite often influenced by ideology, but they are tempered partly by the previous experiences of decision makers and the context in which they work, partly by the social and financial environments in which they arise, and partly by the evidence available on the need for and the effectiveness of specific interventions. The quality of the evidence and its interpretation are often contentious, but as time goes by, the accumulation of well-founded evidence becomes a driving force for the development of policy which can be independent of ideological pressures.

School food and nutrition provides a good example of these principles. Over a century ago, educationalists recognized that hungry children cannot learn. If one accepts the premise that an educated population is of benefit to a country's development and welfare ${ }^{(2)}$, as well as the fulfilment of individuals' human capital, it is important that children are well fed with a balanced diet before they arrive at school and during the school day. The initial focus was on the welfare of children from poorer backgrounds, and free or subsidized food was often the norm ${ }^{(3)}$. As school food and nutrition programmes became more established, however, three issues arose. The first concerned the financial viability of school catering services - is school food a public good, to be paid for from the public purse, or should those able to pay be asked to pay? The second concerned the food itself - what food and drink should be provided? Third, how does one measure the impact of school food in terms of educational, health, social and agricultural outcomes?

The implementation of school food and nutrition programmes worldwide provides diverse sets of answers to these questions. In some countries, subsidized programmes are linked to local agricultural production and support for families and the workforce, and food provision is based on local staple foods ${ }^{(4)}$ (although in others, it may provide a route for disposing of excess production of particular products $)^{(5)}$. In others, universal provision is paid for centrally through taxation, and food is required to meet nutritional standards and inspected on that basis ${ }^{(6)}$. In yet others, school food is essentially a commercial service, built around an extensive offer of food and drink that children themselves are free to choose at break and mealtimes ${ }^{(7)}$. Sometimes provision is built around a combination of these models ${ }^{(8)}$. Finally, some countries eschew school food provision altogether, and children in the main bring snacks or meals from home. Guidance may be available through non-government sources $^{(9)}$, and some government programmes are put in place for vulnerable children ${ }^{(10)}$ to guide local provision.

Demonstrating the impact of school food and nutrition on health, educational and welfare outcomes is a challenge for every country. Investment in evaluation is often limited, intermittent and patchy, and the focus depends on the characteristics of the programme and on government support. Cost-benefit analyses are difficult to undertake, in part because the outcomes may not be evident for years or decades. Since the turn of the millennium, however, a renewed interest worldwide in the role of school food has prompted recognition of the need for data collection and evaluation on the impact of school food with the specific view of informing policy development ${ }^{(11)}$.

An international workshop held in London in January 2012 brought together a diverse group of stakeholders, academics and policy makers from twenty middle- and highincome countries, and from international agencies including the WHO, World Bank and World Food Programme, to examine the evidence base relating to school food and nutrition policy and how it might be strengthened. Through presentations, workshops and discussions in four sessions over two days $^{(12)}$, participants explored the nature of the evidence base, its purpose and context, and made recommendations for developing and linking evidence and policy.

Ten of the papers in this issue are based on presentations and discussions from the workshop. Three ${ }^{(13-15)}$ outline the school food programmes for the four countries of the UK, the USA and Brazil, respectively. All three papers illustrate how, over the last decade, governments have been willing to fund the monitoring of school lunch programmes in order to understand the effectiveness of their implementation in terms of child nutrition, and in the case of Brazil, the economic and agricultural advantages that have also accrued. They also illustrate how the evidence base was used to adjust programmes to increase their effectiveness and how the new understandings, shared internationally, helped to inform domestic decisions.

The next session in the workshop provided opportunities to explore relationships between government decision makers, monitoring and evaluation, and the roles of multiple stakeholders in creating coherent approaches to school food and nutrition programmes that address social and economic as well as nutritional outcomes. The paper by Gelli and Espejo ${ }^{(16)}$ illustrates the complexity of the engagement process. Governments need to provide clear leadership while at the same time ensuring that technical and economic support for implementation is in place. This involves doing work to ensure that there is unanimity among stakeholders (whether on the delivery or receiving end), not only in terms of the need for the programmes and the approaches to implementation, but also including their monitoring and evaluation. Again, sharing lessons between countries is often key to helping to create that unanimity.

It is important to capture the opportunities presented by school food and nutrition programmes to integrate 
complementary approaches to improving eating habits in the population generally and to understanding the collateral benefits of school food and nutrition. Moore et al. ${ }^{(17)}$ identify several contemporary examples in which synergistic approaches to improve children's nutrition, anchored in school food programmes but embracing parallel approaches to changing behaviour in multiple contexts, achieve lasting effects in relation to growth. They also present evidence which shows the opposite: that a lack of integration may lead to faltering of the achievement of desired outcomes. A key theme of their paper is the use of appropriate theoretical frameworks to underpin interventions. This goes beyond the mere integration of policy and evidence to illustrate how comprehensive change can be brought about.

The final presentations in the workshop explored cost-benefit analysis, going beyond the short-term health framework to explore relative returns for investment in terms of value for money. The paper by Nelson ${ }^{(18)}$ facilitated a breakdown of costs and clarified the extent to which investment in an integrated approach to change management around school food produced substantial gains for relatively modest outlays, comparable with the costs of other public health interventions shown to have had the impacts desired ${ }^{(11)}$. This type of analysis, and others which try and capture the impact and costs in relation to longer-term health gains ${ }^{(19,20)}$, highlight that although it may be virtually impossible to assess the longerterm benefits directly, they can be modelled effectively for purposes of policy impact evaluation.

The accretion of the papers in this issue on the value of an evidence base for supporting policy development does not simply demonstrate that good school food and nutrition policy is founded on good evidence. The real gist is that an appreciation of the wider educational, health, social, economic and agricultural context in which school food and nutrition programmes operate and can bring benefits warrants the political long view. Where this is in place, and with the right theoretical underpinning, operating parameters and stakeholder alliances, school food and nutrition programmes are likely to prove especially effective across multiple domains.

Michael Nelson Director

Public Health Nutrition Research Ltd Email: michael.nelson@phnresearch.org.uk

Dr Joäo Breda

Programme Manager

Nutrition, Physical Activity and Obesity Programme World Health Organization - Regional Office for Europe Copenhagen, Denmark Email: JBR@euro.who.int

\section{References}

1. World Health Organization (2013) Millennium Development Goals (MDGs). http://www.who.int/topics/millennium_ development_goals/about/en/index.html (accessed April 2013).

2. World Health Organization (2009) Interventions on Diet and Physical Activity: What Works. Summary Report. Geneva: WHO; available at http://www.who.int/dietphysicalactivity/ summary-report-09.pdf

3. Andresen A \& Elvbakken KT (2007) From poor law society to the welfare state: school meals in Norway 1890s-1950s. J Epidemiol Community Health 61, 374-377.

4. Partnership for Child Development (2013) The PCD Home Grown School Feeding Programme - A programme brief. http://www.hgsf-global.org/en/component/docman/doc_ details/301-the-pcd-home-grown-school-feeding-programmea-programme-brief (accessed April 2013).

5. Yeoman B (2013) Is the US government making children fat? Nieman Reports, Spring 2013. http://www.nieman.harvard. edu/reports/article/101174/Is-the-US-Government-MakingChildren-Fat.aspx (accessed April 2013).

6. Finnish National Board of Education (2008) School meals in Finland. Investment in learning. http://www.oph.fi/download/ 47657_school_meals_in_finland.pdf (accessed April 2013).

7. US Department of Agriculture, Food and Nutrition Service (2012) National School Lunch Program. http://www.fns.usda.gov/cnd/ Lunch/AboutLunch/NSLPFactSheet.pdf (accessed April 2013).

8. Nelson M (2011) The School Food Trust: transforming school lunches in England. Nutr Bull 36, 381-389.

9. Nutrition Australia (2008) What's for Lunch? http://www. nutritionaustralia.org/national/resource/whats-lunch (accessed April 2013).

10. Australian Government, Department of Education, Employment and Workplace Relations (2012) The School Nutrition Program. http://deewr.gov.au/school-nutritionprogram (accessed April 2013).

11. Bundy DAP, Burbano C, Grosh M et al. (2009) Rethinking School Feeding; Social Safety Nets, Child Development, and the Education Sector. Joint Publication of the World Food Programme and The World Bank, Directions in Development. Washington, DC: The World Bank.

12. Nelson M \& Breda J (2013) School food research: building the evidence base for policy. Public Health Nutr 16, 958-967.

13. Adamson A, Spence S, Reed L et al. (2013) School food standards in the UK: implementation and evaluation. Public Health Nutr 16, 968-981.

14. Hirschman J \& Chriqui JF (2013) School food and nutrition policy, monitoring and evaluation in the USA. Public Health Nutr 16, 982-988.

15. Sidaner E, Balaban D \& Burlandy L (2013) The Brazilian school feeding programme: an example of an integrated programme in support of food and nutrition security. Public Health Nutr 16, 989-994.

16. Gelli A \& Espejo F (2013) School feeding, moving from practice to policy: reflections on building sustainable monitoring and evaluation systems. Public Health Nutr 16, 995-999.

17. Moore L, de Silva-Sanigorski A \& Moore SN (2013) A socio-ecological perspective on behavioural interventions to influence food choice in schools: alternative, complementary or synergistic? Public Health Nutr 16, 1000-1005.

18. Nelson M (2013) School food cost-benefits: England. Public Health Nutr 16, 1006-1011.

19. Vale L, Adamson A, Critchley J et al. (2011) Economic evaluation: evaluating the short-term impacts of the school food policy and experimental modelling of longer term impacts. http://phrc.lshtm.ac.uk/papers/PHRC_B5-07A_Final_ Report.pdf (accessed April 2013).

20. Conlon G (2008) Estimating the economic impact of healthy eating. http://www.childrensfoodtrust.org.uk/research/ economics/economic-case (accessed April 2013). 